\title{
Learning Theories in the context of teaching Law
}

\author{
Nandini S. Boodia-Canoo
}

\begin{abstract}
The following is a reflective case study on common approaches to teaching Law in higher education, and how these may be informed by learning theories. The paper looks specifically at Social Learning Theory, Constructivism and Cognitive Load Theory. Following a critique of certain practices, suggestions are made to encourage further evolution of methods relevant to teaching problem-solving skills to Law students at undergraduate level.
\end{abstract}

\section{Introduction}

The previous academic year, I was fortunate to be a student again by enrolling for the Postgraduate Certificate in Higher Education course at the University of Greenwich. Completing the programme whilst working full time proved challenging yet genuinely rewarding. The opportunity to examine learning theories in some detail led me to reflect on their application in the context of teaching Law at university. Social Learning Theory and Cognitive Load Theory in particular raise important questions for the teaching of a social science that requires the acquisition of practical skills. The pedagogy of legal education remains a niche area, and it is hoped that the thoughts and arguments presented here will stimulate reflection and debate.

\section{Teaching Law - how and why}

To place the arguments in context for readers of different disciplines or jurisdictions, it should be noted that the process of qualifying as a lawyer in the UK is divided into three stages which can be summarised thus: an academic stage, a professional education stage and a practical training stage. It is the academic stage which is covered at undergraduate level. In order to progress to the professional education stage, ${ }^{1}$ a "Qualifying Law Degree" (QLD) must be obtained, ${ }^{2}$ the requirements of which are regulated by the relevant professional bodies. $^{3}$

\footnotetext{
${ }^{1}$ At the professional education stage the path splits. Those intending to become solicitors complete the Legal Practice Course, now soon to be replaced by the Solicitors Qualifying Examination (SQE), whereas those intending to qualify as a barrister undertake a Bar course (previously named the Bar Professional Training Course/Bar Vocational Course). The SQE will not require a QLD in the traditional sense, and since last autumn, elements of the Bar course may be completed at different points in time.

2 The Graduate Diploma in Law for non-law graduates.

3 The Solicitors Regulation Authority and the Bar Standards Board. See 'Academic Stage Handbook' <https://www.sra.org.uk/students/academic-stage/> accessed 3 January 2020.
} 


\section{Literature Review}

Without much prior knowledge of learning theories, after studying a selection as part of the programme, I noticed one in particular: Social Learning Theory (SLT) as explored by Albert Bandura (1971). The key conceptualisation flowing from Bandura's research is that learning takes place primarily by observation. Thus, new behaviours are acquired not solely through direct experience, but through the observation of others (ibid. p.5), an exercise more accurately evoked through Bandura's choice of the word 'modelling' (ibid. p.5). Within his theory, certain cognitive processes are deemed essential, which are as follows:

\section{Attention}

Attentional processes are significant, because mere exposure to a concept will not induce learning by itself. A presence of mind is thus required at the outset to allow for learning to take place. Bandura posits that "associational preferences" are significant in this respect, since opportunities for learning will vary with context, and inevitably, some members of a social setting command greater attention than others.

\section{Retention}

This refers to the cognitive function of memory. Without the ability of long-term recall, observed behaviour cannot be repeated. Bandura recognises that not all observational learning occurs immediately, which accentuates the requirement of adequate recollection.

\section{Motoric reproduction}

In order to reproduce modelled behaviour, a person would have to possess the relevant set of skills. A lack of such skills, which may exist simply owing to physical limitations, would prevent reproduction of learned behaviour. Bandura gives the example of a child who has learned the associated movements for driving a car, but without suitable height will be unable to set the vehicle in motion.

\section{Reinforcement and motivation}

This final requirement illustrates Bandura's proposition that unless the behaviour in question is desired or otherwise received in a favourable manner, it is unlikely to reproduced, even if all the preceding processes are in place. As such, reward and punishment play a key role in encouraging observational learning.

I came to realise that I have previously employed Bandura's propositions extensively. This is likely because observational learning is linked to the most instinctive form of teaching: demonstrative instruction. "Look at me... pay attention! Watch what I am doing. Now do the same.... very good, well done!" - these are the sentences through which children are taught basic skills from an early age. Perhaps inevitably therefore, much of that approach channelled itself into my teaching practice, particularly in the delivery of modules concerned with practical skills. Learning by observation is the preferred method put in place for oral competencies such as advocacy or client interviewing. The student is expected to learn by observing the teacher, a lawyer in a video clip or, indeed, fellow students in practice sessions.

The widespread acceptance of this approach notwithstanding, the method has marked limitations, particularly in legal education. The primary skill to be acquired is that of incisive 
legal analysis. Arguably, the ability to discern relevant material from irrelevant detail can be demonstrated easily enough, but more complex cognitive processes well beyond attention or recollection must be developed before the behaviour can be reproduced.

More broadly, the question of learning by observation in higher education raises a significant issue that must be considered in the context of a diverse student body. Bandura highlights a fundamental notion with regard to his first stipulation, namely attention. He states (Bandura, op.cit., p.7):

"The functional value of the behaviors displayed by different models is highly influential in determining which models will be closely observed and which will be ignored.

Attention to models is also channelled by their interpersonal attraction."

What then determines the 'functional value' of a model? For many students, it may boil down to whether they can relate to their teacher. At a time when students, especially from ethnic minorities, do not always feel they can identify with staff at their institution (Greenwich Students' Union, 2019), this raises pertinent questions. For example, how is learning affected in a department (or indeed an institution) where the composition of teaching staff does not mirror the student body? While there is a growing scholarship on issues of inclusion and diversity, more initiatives and focused research in this area are required.

Furthermore, a crucial issue with this type of learning theory is the significant number of assumptions it makes: it presupposes a certain 'baseline' in all learners with respect to mental and physical capacity. Proponents of this approach take these presumptions for granted (Wenger, 2008), which is problematic. It has been demonstrated that, for individuals with certain conditions such as autism, this method is less advantageous (Yang et al. 2017). As a consequence, if taken as a dominant understanding of how learning occurs, it may also create stigma for those who do not meet the assumed baseline of ability.

After contemplating these issues, it is with some shame I came to realise that my expectations of my students have frequently been based on assumptions too. Issues of mental capacity would be hard to discern, of course, unless disclosed by students. But assumptions are made even regarding physical abilities. For example, students are required to stand in Advocacy classes when delivering their arguments, including during the final assessment. While in my previous cohorts all appeared sufficiently able-bodied to do so, I assumed as much without enquiry. The basic instruction of letting me know if they are comfortable to stand for the duration required would be a simple measure for deconstructing assumptions in the assessment process.

It is worth noting that it may have not previously occurred to me to address such assumptions, because no-one enquired into my capacities when I was studying practical skills as a student. The temptation to teach precisely the way one was taught, or in the manner a subject is habitually taught, is unfortunately compelling.

To return to the limitations of SLT and observational learning for the time being, numerous assumptions as to learner ability is only one the criticisms that may be leveraged against this conceptualisation of learning. Another outcome I have observed, which may arise if there is a heavy emphasis on 'modelling' in teaching, is that of basic imitation without a critical thought process. This is perhaps more drastically illustrated in the context of written skills. 


\section{Teaching legal skills - a case study}

As part of my teaching duties during the previous academic session, I was involved in the delivery of a module called 'Problem Solving and the Law'. It is a compulsory Level 4 (Year 1), fifteen-credit module on the Bachelor of Laws degree (LLB) at the University of Greenwich which takes place in the autumn term, and thus, at the very beginning of undergraduate studies for new Law students. The module requires students to work on two given scenarios for the entire term as a way to acquire problem solving skills. This approach to legal studies at undergraduate level is rather new but presents the preferred mode of instruction at post-graduate level for the professional courses which lead to qualification.

The problem-based way of instruction is rooted in constructivism and the notion that learners are to actively participate in the creation of knowledge and not to be passive receivers (Pritchard and Woollard, 2010). Proponents of the constructivist approach expound on its merits by emphasising learner independence, critical thinking and real-life problem solving, amongst others qualities that this teaching approach fosters (ibid., p.45).

Prior to studying learning theories, I had only an instinctual (yet deeply-felt) reservation to employing this type of teaching strategy at Level 4. I considered that at such an early stage, students lacked the necessary knowledge (meaning the basic contents of statute and case law) to benefit from a problem-based learning approach. After the conclusion of the module and the final marking process, as well as acquiring a deeper understanding of learning theories in the meantime, I feel my concerns were valid.

\section{Evaluation}

Within weeks, it became evident that students were indeed very much struggling with this level of learner independence and critical thinking skills expected of them at the outset of their studies. This is dealt with on the course by exceedingly prescriptive modelling of how the problem scenarios provided are supposed to be tackled. Thus, unattainable constructivist expectations are ostensibly fulfilled, but by little more than observational learning. The students were shown how to write an answer - through instruction and written feedback on coursework - with no deviations from the model permitted.

Requiring strict adherence to a model answer runs counter to every proclaimed benefit of problem-based learning. Far from developing critical thinking in students, the pursuit is reduced to the most basic outcome derived from observational learning: reproduction.

The shortcomings of that approach became starkly evident for me when marking the final assessment, consisting of one written answer that had received detailed prior feedback, and one answer which had been composed by students without extensive guidance from their tutor. Frequently, the second answer fell short, on the very same aspects the student had purportedly already 'learned' when composing the first answer. In such circumstances it was clear that no actual learning had in fact occurred, for the 'knowledge' was not being replicated. It also put into question the value of the feedback provided, which manifestly was not developmental.

This serves to illustrate the limitations of the observational learning and teaching approach. If the modelling (whether by direct instruction or feedback) is highly prescriptive, a frequent 
outcome will be merely mechanic imitation. The learner will not have grasped the reasoning behind the instruction or the feedback, and thus will be unable to successfully apply the concept to a separate situation. In the case of the module discussed, students experience the lowest manifestation of the two teaching approaches, with the ambitious constructivist aspirations of PBL remaining out of reach as a diminished form of observational teaching is employed to achieve a basic replicative outcome.

What could be a potential alternative? Cognitive Load Theory (CLT) takes a critical stance on constructivist approaches. It draws a distinction between what is termed 'biologically primary knowledge' and 'biologically secondary knowledge', arguing (in broad terms) that the former is acquired through evolutionary cognitive abilities which cannot be taught. ${ }^{4}$ Only the latter, presenting knowledge obtained for social or cultural reasons can be - and are taught (Pritchard and Woollard, ibid.).

CLT stresses the importance of long-term memory as the place where learning is stored, and it is claimed that "[t]he purpose of instruction is to increase the store of knowledge in long-term memory. If nothing has changed in long-term memory, nothing has been learned." (Pritchard and Woollard, ibid. p.24.) Knowledge, in the sense of biologically secondary knowledge that makes up curricula, consists of "domain-specific schemas that must be acquired" and which "[provide] a complete description of expertise." (Ibid.)

This lays out an interesting hypothesis to a dilemma I have been pondering since I started to work as a lecturer. I have wondered how do I teach what is arguably the main skill emanating from any Law module: legal reasoning. The question has puzzled me for a long time, and occasionally I have queried whether it is teachable at all. The module described above aims to focus specifically on that particular skill, but, in my view, largely fails to do so. The question arises as to why this difficulty exists.

Legal reasoning could be considered simply an advanced version of basic problem solving. It is a process that similarly requires the application of plain logic, but with the difference of operating within the parameters of a certain set of rules. If taken as such, legal reasoning would amount to what CLT terms biologically primary knowledge, and therefore would not actually be teachable. What is teachable, and what represents 'expertise', are, as noted above, domain-specific schemas, meaning in this instance patterns of thoughts relevant to legal practice. This insight has profound implications for a conceptual understanding of legal education. If the skill I am seeking to teach is not acquired through instruction (because it cannot be taught) but through exposure to the relevant patterns of thought, my entire approach must be designed to implement that; otherwise the endeavour is futile.

Research related to CLT indicates that, in order to achieve expertise in an area, domainspecific knowledge must be acquired first, as shown by de Groot's work with chess players (Pritchard and Woollard, ibid.). This supports my submission as to why I consider the problem-solving approach at Level 4 not a useful exercise. "We must carefully consider whether many recently popular instructional techniques associated with inquiry, problembased or constructivist learning procedures that do not emphasise domain-specific knowledge have any base in our cognitive architecture." (Ibid., p. 25) As already mentioned, problem-based learning as part of legal studies commonly takes place at post-graduate

\footnotetext{
${ }^{4}$ Sweller, J., Ayres, P. and Kalyuga, S. (2011) Cognitive Load Theory. New York: Springer.
} 
level, which indeed seems a more suitable point in time for this method. The trend to introduce this approach at undergraduate level is recent, and no doubt partly engineered with the aim to increase the employability appeal of the LLB.

What has become clear to me however is that the timing and manner of instruction is crucial for the exercise to be successful. Constructivist techniques are useful and have their validity, but only after a sufficient grounding in basic understanding has been achieved. Further, the instruction method of SLT ("observe and reproduce") should not become the default fall-back teaching approach, even if it is liable to be treated as such.

\section{Conclusion}

Where praxis-orientated subjects are concerned, learning theories are easily dismissed as hypothetical concepts of remote speculation. Yet, on closer view, they present a wide repository of inspiration and teachers of Law should be encouraged to engage more with the various hypotheses of how learning occurs. Despite the strong psychological pull to shirk innovation which perhaps inevitably accompanies the delivery of a regulated degree, it is important for instructors to assert their agency in reviewing and using inherited course materials. This also applies to the adoption of modern trends, for all strategies must be rigorously tested, and nothing is as effective and insightful for doing so as the lived classroom experience.

Part of the process is willingness to dismantle personally held assumptions we as teachers hold about students and teaching and learning processes. Reflection, whether as I have done here in this paper or in discussions with colleagues, is the driver for the requisite sustained improvement of legal education.

\section{Reference list}

Bandura, A. (1971) Social Learning Theory. New York: General Learning Press. ISBN: 9780382250255.

Greenwich Students' Union (2019) Minority Ethnic (BAME) Student Consultation Group: Final Recommendations [unpublished report]. University of Greenwich.

Pritchard, A. and Woollard, J. (2010) Psychology for the Classroom: Constructivism and Social Learning. Oxford: Routledge. ISBN: 9780203855171.

Sweller, J., Ayres, P. and Kalyuga, S. (2011) Cognitive Load Theory. New York: Springer. ISBN: 9781441981264.

Wenger, E. (2008) 'A Social Theory of Learning', in Contemporary Theories of Learning, ed. by Illeris, K. Oxford: Routledge, 216. ISBN: 9780415473446.

Yang, Y., Tian, Y., Fang, J., Lu, H., Wei, K., Yi, L. (2017) 'Trust and Deception in Children with Autism Spectrum Disorders: A Social Learning Perspective', Journal of Autism and Developmental Disorders 47, 615. Available at:

<https://link.springer.com/article/10.1007/s10803-016-2983-2> (accessed 18 November 2019). 